\title{
Impact of Physical Activity and Medication Adherence on the Seizure Frequency and Quality of Life of Epileptic Patients: A Population Study in West Texas
}

\author{
YoonJung Lee, ${ }^{1}$ Yeseul Ahn, ${ }^{1}$ and Luca Cucullo $\mathbb{D}^{2}$ \\ ${ }^{1}$ Department of Pharmaceutical Sciences, Jerry H. Hodge School of Pharmacy, Texas Tech University Health Sciences Center, \\ Amarillo, TX 79106, USA \\ ${ }^{2}$ Department of Foundation Medical Studies, Oakland University William Beaumont School of Medicine, Rochester, MI 48309, USA \\ Correspondence should be addressed to Luca Cucullo; lcucullo@oakland.edu
}

Received 20 August 2021; Accepted 4 January 2022; Published 18 January 2022

Academic Editor: Alberto Raggi

Copyright (C) 2022 Yoon Jung Lee et al. This is an open access article distributed under the Creative Commons Attribution License, which permits unrestricted use, distribution, and reproduction in any medium, provided the original work is properly cited.

\begin{abstract}
Epilepsy is a neurological disease that affects $1-3 \%$ of the population. People with epilepsy (PWE) have poor physical and psychological health and a lower quality of life (QOL) than people without epilepsy. Moreover, PWE has more comorbid conditions (obesity, depression) than general populations. Physical activity (PA) has been reported to have various positive physical and psychological effects in PWE. Meanwhile, poor medication adherence is one of the main precipitating factors for seizure triggers. This study assessed the impact of PA and medication adherence on the seizure frequency and QOL for PWE at the Epilepsy Foundation, West Texas (EFWT). Our results indicate that PA is positively associated with the quality of life and negatively associated with the seizure frequency for PWE at EFWT, which suggests that physically active PWE tend to have fewer seizures and better QOL. Medication adherence did not affect the seizure frequency or QOL in our study. Yet, it is still crucial to encourage medication adherence for PWE since nonadherence is a known seizure promoter. Findings from this study highlight the continuous need to utilize available resources and implement programs to promote physical activity and medication adherence for better seizure control and QOL in PWE at EFWT.
\end{abstract}

\section{Introduction}

Epilepsy is one of the most common neurological diseases globally, affecting $1-3 \%$ of the population, 50 million worldwide, and 5.1 million in the U.S. [1-3] Epilepsy is a neurological syndrome defined by having two or more spontaneous, unprovoked seizures separated by at least 24 hours [4]. An epileptic seizure is a transient occurrence of signs and symptoms due to abnormal excessive or synchronous neuronal activity in the brain $[4,5]$. Focal and generalized seizures are the two main types of seizures, where generalized tonic-clonic seizures involve a loss of consciousness with generalized body stiffening and jerking [6]. People with epilepsy (PWE) develop cognitive dysfunction over time as the disease progresses [7, 8]. Furthermore, PWE experience several adverse drug events related to the use of antiepileptic drugs (AEDs), such as weight gain, osteoporosis, fatigue, drowsiness, and other side effects [9-12].

Besides the negative impact of epilepsy on physical health, epilepsy-related stigma negatively impacts an individual's life, including economic and employment status, psychological well-being, social interactions, self-esteem, and overall health [13]. Furthermore, several studies reported epilepsy-related stigma to influence medication adherence negatively $[14,15]$. Medication adherence rate for PWE ranges between $30 \%$ and $60 \%$, with an indirect correlation between the degree of disease-related stigma and medication adherence [16-18]. PWE with higher levels of disease-related stigma have lower medication adherence and poor compliance to medication, which may lead to precipitated seizures $[15,19]$.

PWE, with lifestyle restrictions, have more comorbid conditions than general populations. $27 \%$ to $84 \%$ of PWE 
have at least one comorbid medical condition, and nearly every PWE will experience a comorbid medical condition at some point during the treatment $[20,21]$. Comorbid conditions that are significantly higher in PWE than general populations include medical diseases (e.g., musculoskeletal disorders, chronic pain disorders, migraine, arthritis, obesity, fractures), psychiatric diseases (e.g., depression and anxiety), and cognitive diseases (e.g., ADHD and learning disability) [21].

When all these factors (e.g., seizures, adverse drug events from AEDs, stigma, other comorbidities, and lifestyle restrictions) are summed up together, they negatively affect the overall quality of life (QOL) of PWE. As a result, PWE have a lower QOL than people without epilepsy [22, 23]. PWE especially have lower scores in physical and psychosocial areas. This observation is potentially due to epilepsyassociated lifestyle restriction and epilepsy-related stigma that leads to lower self-esteem and higher rates of anxiety and depression $[24,25]$.

Physical activity (PA) is defined as any bodily movement produced by skeletal muscles in daily life that results in energy expenditure and can be categorized into occupational, sports, conditioning, household, or other activities [26]. PA has various positive physical and psychological effects in PWE. In terms of PA's positive physical effect in PWE, one potential explanation is physical activity promoting general health, well-being, and improving cardiovascular function, thereby aiding to manage physical comorbidities (obesity) commonly observed in PWE [27]. Additionally, PA can exert positive psychological effects by improving mood and reducing stress, one of the most frequently selfreported precipitants of seizure, in PWE [27]. The beneficial effects of PA include comorbidity management, reduction in adverse drug events by antiepileptic drugs, overall improvements in health, QOL, and behavioral outcomes [22, 27-30]. For example, a study conducted by Volpato et al. reported better QOL and lower seizure frequency when PWE had higher physical activity and aerobic capacity [22]. Another study by Hafele et al. reported a positive association between PA and QOL and negative associations between PA and depression, anxiety, and adverse effects of medication in PWE [30]. Limited studies also evaluated the effects of PA in seizure frequency. These studies had mixed results, with a significant decrease in seizure frequency reported in three studies, no change in seizure frequency in the remaining studies [22, 29, 31-33]. None of the studies reported increased seizure frequency during the exercise programs. The exact mechanism of how physical activity helps to reduce seizures is unknown. Still, a few potential mechanisms of physical activity reducing seizures include (1) PA to reduce neuroinflammation, which is a known trigger for epilepsy, and (2) improved mitochondrial function to generate more energy sources for neurons, which helps for stabilization of neuronal activity [34-36].

Furthermore, all of these studies reported positive outcomes of PA. These positive outcomes include increased physical capacity and improvement in QOL, general health, psychological state, and emotional status [22, 29, 31-33]. Up to date, there is only one study that has evaluated the associ- ation between physical fitness and the risk of epilepsy at a later life. A prospective Swedish study conducted on male participants $(n=1,173,079)$ analyzed the association between cardiovascular fitness at age 18 years and the future risk of epilepsy [37]. In this study, low cardiovascular fitness early in life was associated with an increased risk of epilepsy later in adulthood, with people in low cardiovascular fitness at almost twice an increased risk of having epilepsy compared to people in high cardiovascular fitness [37]. Yet, further extensive and additional studies are required to confirm this observation.

Discouraging PA in PWE has been the norm in the past. In 1968, the American Medical Association (AMA) recommended restricting PWE from engaging in physical activity due to fear of fall injury or exercise-induced seizures [28]. Even after AMA officially removed this restriction, PWE tend to be less active than the general population $[38,39]$. Furthermore, PWE have both common barriers (e.g., lack of time and motivation) to engage in PA observed in general people and additional barriers of engaging in PA, such as fear of seizure occurrence, fear of seizure-related injuries, and incorrect advice from medical professionals [40]. As a result, obesity remains one of the most common comorbidities reported in PWE.

With a recent shift in medical recommendations to encourage sports participation in PWE, International League Against Epilepsy (ILAE) Task Force offered general guidance for the involvement of PWE in sports activities by dividing sports activities into three categories [41]. These categories are based on the potential risk of injury or death, with group 1 sports with no significant additional risk and group 3 sports with major risk [41]. Furthermore, the development of the seizure monitoring device can encourage physical activity in PWE. Embrace is the first seizure detection device that received clearance from the FDA in 2018. This device monitors the generalized tonic-clonic seizures and sends an alert to summon caregivers' help. Embrace detects seizure by a combination of two systems: (1) Accelerometry (ACM) monitoring system that detects wrist acceleration and vibration during the seizure attack and (2) electrodermal activity (EDA) monitoring system that quantifies physiological changes related to the sympathetic nervous system activity. The device alerts the caregivers only when there is a combination of the seizure involving convulsive movements and a spike in autonomic stress with $\geq 20$ seconds duration [42]. Yet, up to date, no data is available that has assessed PWE's awareness of this device.

The beneficial effects of PA in PWE have been well reported in studies by Volpato et al. and Hafele et al. [22, 30] In this study, we wanted to assess the impact of PA and medication adherence on seizure frequency and QOL. The primary outcome of the program evaluation project was to evaluate the effect of PA and medication adherence on seizure frequency and QOL for PWE at the Epilepsy Foundation, West Texas. Additionally, we have compared male patients and female patients to assess any gender differences for our findings. The secondary outcome of our project was to obtain the demographic information of PWE, to assess PWE's perception regarding physical activity, 
potential barriers of physical activity, PWE's awareness on the seizure detection device, seizure types, and seizure frequencies, and to assess the areas of care that potentially require an improvement for PWE at the Epilepsy Foundation, West Texas (EFWT).

\section{Methods}

2.1. Setting and Study Population. Epilepsy Foundation, West Texas, is one of the regional offices of the Epilepsy Foundation Texas (EFTX) that provides programs and services for PWE living in the West Texas area, including Amarillo and Lubbock. The programs and services offered include medical clinics staffed by a neurologist, nurse, social worker, prescription assistance, information and referral services, and education programs. Currently, about 150 registered patients receive care from this foundation. Participation in this study was solely voluntary and did not affect the current care treatment of the patient in either case. The EFWT staff responsible for checking in patients for onsite care conducted a survey only for patients who voluntarily agreed with verbal consent. Also, patients had full authority to answer or not answer any of the survey questions. None of the survey questions contained identifiable patient information per HIPAA guidelines.

Additionally, all patient data were deidentified before the data analysis process to ensure confidentiality. Since this project was a program evaluation project without direct patient intervention, the TTUHSC Quality Improvement Review Board determined this project as a program evaluation project. Thus, this project did not require a further institutional review.

\subsection{Assessment of Demographic Information, Physical Activity, Quality of Life, and Medication Adherence}

2.2.1. Demographic Information. We requested a patient to fill out the physical survey form voluntarily for data collection. Inclusion criteria were adult patients ( $\geq 18$ years old) currently receiving medical treatment at Epilepsy Foundation, West Texas. Exclusion criteria were pediatric patients ( $<18$ years old), an intellectual disability, or other health conditions limiting their capacity to complete the selfadministered survey. The survey consisted of 79 total questions that assessed four different areas: demographic information, physical activity, quality of life, and medication adherence. A survey was available in both English and Spanish. For demographic data, there were 20 questions to obtain basic information, health-related information, perception of physical activity and seizure detection device, characteristics of seizures, current antiepileptic drugs (AEDs), and other prescription or over-the-counter drugs, and a patient selfreported seizure frequency. For seizure frequency, we used the median seizure frequency [43]. We obtained the survey instruments from the Social and Behavioral Instruments (SABI) database [44], which provides the validated measurement instruments to the researcher to assess physical activity, quality of life, and medication adherence. International Physical Activity Questionnaire (IPAQ)-long version, World
Health Organization Quality of Life-BREF (WHOQOLBREF), and Simplified Medication Adherence Questionnaire (SMAQ) were the three survey instruments utilized because of their validity and reliability established from multiple studies with extensive use in various settings [45-47].

2.2.2. Quantification and Categorization of Physical Activity. We used an IPAQ-long version to measure physical activity in people with epilepsy [45]. IPAQ assesses physical activity in the set of domains, including leisure-time physical activity, domestic and gardening (yard) activities, work-related physical activity, and transport-related physical activity. Then, after calculating Metabolic Equivalent Task minutes per week (MET-minutes/week), physical activity variables were categorized as follows: (1) Low-no activity or some activity reported, but not enough to meet moderate or high categories. (2) Moderate-either one of the following three categories: (a) 3 or more days of vigorous-intensity activity of at least 20 minutes per day OR (b) 5 or more days of moderate-intensity activity and/or walking of at least 30 minutes per day OR (c) 5 or more days of any combination of walking, moderate-intensity, or vigorous-intensity activities achieving a minimum of at least $600 \mathrm{MET}-\mathrm{min} /$ week. (3) High-any one of the following two criteria: (a) vigorous-intensity activity on at least three days and accumulating at least 1500 MET-minutes/week OR (b) 7 or more days of any combination of walking, moderate-, or vigorousintensity activities accumulating at least 3000 MET-minutes/ week. Patients who reported exercising $\geq 16$ hours per day were excluded under the assumption that an individual requires 8 hours per day for sleeping.

2.2.3. Assessment of Quality of Life. World Health Organization Quality of Life-BREF (WHOQOL-BREF), a short version of the WHOQOL-100, was used to assess QOL in PWE. The choice of survey tool was made to compare QOL between PWE and people without epilepsy. Unlike the Quality of Life in Epilepsy Inventory (QOLIE), which can only be administered in PWE, WHOQOL-BREF is a nondisease-specific tool with broader application.

The questionnaire consists of a total of 26 questions, 24 questions to assess four domains (physical health, psychological health, social relationships, environment), and two questions to evaluate an individual's overall perception of his quality of life (overall QOL) and an individual's overall perception of his health (general health) [46]. The answers ranged on a scale of 1 to 5 , with higher scores reporting better QOL, except for three negatively phrased questions with higher scores indicating lower QOL [46]. The raw score of each domain was calculated and then transformed into a 0-100 scale for an individual patient using an equation and table from the WHOQOL-BREF manual. After obtaining the study participants' average, we compared these numbers to the WHOQOL US average QOL scores for healthy subjects and chronically ill patients reported in the literature [48].

2.2.4. Assessment of Medication Adherence. We utilized the Simplified Medication Adherence Questionnaire (SMAQ) 
that consists of 6 items designed to assess medication adherence [47]. In this survey, a positive response to any of the qualitative questions indicates a nonadherence to the medication. These qualitative questions include (1) $\geq 2$ doses missed over the past week and $(2) \geq$ two days of not taking any medication during the past three months [47].

2.3. Statistical Analysis. A descriptive analysis of the collected data was carried out using Excel 2013 to organize and evaluate the demographic information, MET-minutes/ week, physical activity categories (low, moderate, and high), quality of life domain scores, and medication adherence rate. Statistical analysis was carried out by GraphPad Prism 8 (GraphPad Software Inc., San Diego, California, USA). Spearman's correlation test was used to evaluate the correlation between physical activity based on MET-minutes/week and the seizure frequency. ANOVA test followed by Dunn's multiple comparisons test was used to compare the seizure frequency between three groups with different physical intensity categories (low, moderate, and high). Pearson's correlation test was used to evaluate the correlation between physical activity and the six parameters of quality of life. ANOVA test followed by Tukey's test was used to compare the quality of life between three groups (people with epilepsy, chronically ill patients, and healthy individuals) and compare the quality of life between three groups with different physical intensity categories. A Student's unpaired $t$-test was used to compare the seizure frequency between the medication adherent and nonadherent groups.

\section{Results}

A Total of 24 Surveys Were Collected in the Study: The Findings of our Study Are Summarized in Figures 1-5

3.1. Physical Activity and Seizure Frequency. Five PWE were in the low physical activity category, eight PWE were in the moderate physical activity category, and six PWE were in the high physical activity category. Overall, there was a moderate negative correlation between physical activity (METminutes/week) and seizure frequency, indicating physical activity to be associated with lower seizure frequency $(r=-0.5266$, Spearman's correlation test, Figure 1(a)). PWE in the high physical category had substantially lower seizure frequency than the other two groups (low and moderate physical categories) without statistical significance (one-way ANOVA test and Dunn's multiple comparison test) (Figure 1(b)).

3.2. Physical Activity (PA) and Quality of Life (QOL). Overall, there was no correlation between PA and domain 3 (social), with weak correlations between PA and domain 1 (physical), PA and domain 2 (psychosocial), and PA and domain 4 (environment) without statistical significance $(r=0.3023, p=0.2228$, Figure $2(\mathrm{a}) ; r=0.3194, p=0.1963$, Figure 2(c), $r=0.3508, p=0.1535$, Figure 2(d), $r=-0.0919$, $p=0.7257$, Figure 2(e), $r=0.2839, p=0.2537$, Figure 2(f)). For overall health, there was a moderate positive correlation with statistical significance between physical activity (MET- minutes/week) and seizure frequency $\left(r=0.5388,{ }^{*} p=\right.$ 0.0210, Pearson's correlation test, Figure 2(b)).

3.3. Quality of Life. QoL scores for PWE were similar to the general QOL scores of the chronically ill patients in the U.S. One-way ANOVA test followed by Tukey's comparison has demonstrated PWE patients to have significantly lower scores than healthy patients in the U.S. for all parameters of QOL except the overall QOL (Figure 3(a)).

Among PWE, when we compared QOL scores between three groups with different exercise intensities, PWE in the high physical activity category had substantially higher QOL scores than the other two groups. One-way ANOVA test followed by Tukey's comparison has demonstrated PWE with high physical activity having significantly higher scores than the other two groups in two domains, psychosocial health $\left({ }^{*} p=0.0416\right)$ and environment $\left({ }^{*} p=0.0349\right)$ (Figure 3(b)).

3.4. Medication Adherence. Fifty-two percent of patients were adherent to medication, and forty-eight percent were nonadherent (Figure 4(a)). There was no difference in seizure frequency between the medication adherent and nonadherent groups (Student's unpaired t-test, Figure 4(b)) There was no difference in medication adherence for PWE with different physical activity intensities (Student's unpaired $t$-test, Figure 4(c)). There was no difference in QOL in the medication adherent group versus the nonadherent group (Student's unpaired $t$-test, Figure 4(d)).

3.5. Male vs. Female. There was no difference in seizure frequency between the two groups (Figure 5(a)). There was no difference in physical activity (MET per week) between the two groups (Figure 5(b)). There was no difference in the number of patients with different exercise intensities (low, moderate, and high) per group (Figure 5(c)). There was no difference in medication adherence between the two groups (Figure 5(d)). There was no difference in QOLs for all parameters between the two groups (Figure 5(e)).

3.6. Characteristics of People with Epilepsy (PWE). The characteristics of the participants are summarized in Tables 1(a)-1(d).

Basic information: the demographic information (age, gender, marital status, ethnicity, health insurance status, education, occupation, and income level) and obesity status are listed in Table 1(a). The collected information suggested patients' age in a wide range (19-70 years old), more males than females, nearly half of patients having obesity and unmarried, and the majority of patients being either White or Hispanic. In terms of socioeconomic factors, most patients were underinsured, had lower education levels, were unemployed, and had low to no income.

Health-related information: most common comorbidities were arthritis, hypertension, asthma, and migraine/ headache. A small number of respondents had mental illnesses (bipolar disorder, anxiety, and depression). More than one-third of the PWE were smokers. Since some patients had $\geq 2$ conditions, the final percentage was not equal to $100 \%$ (Table $1(\mathrm{~b})$ ). 


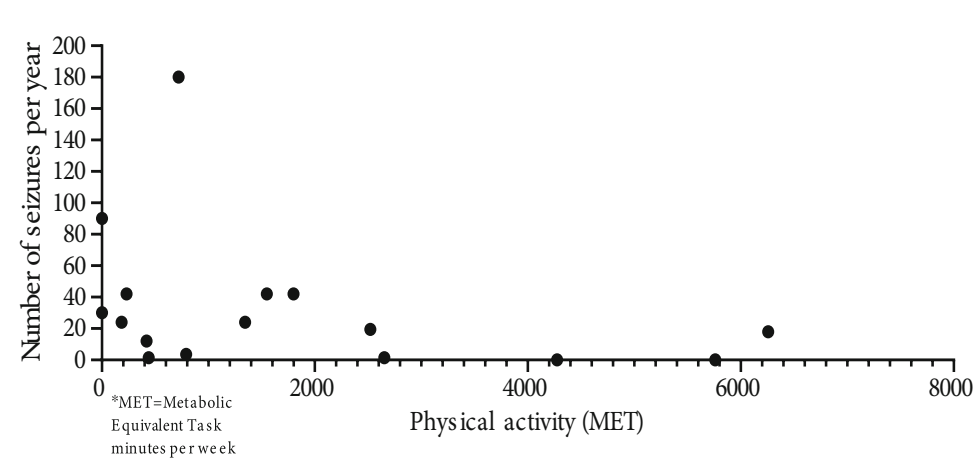

(a)

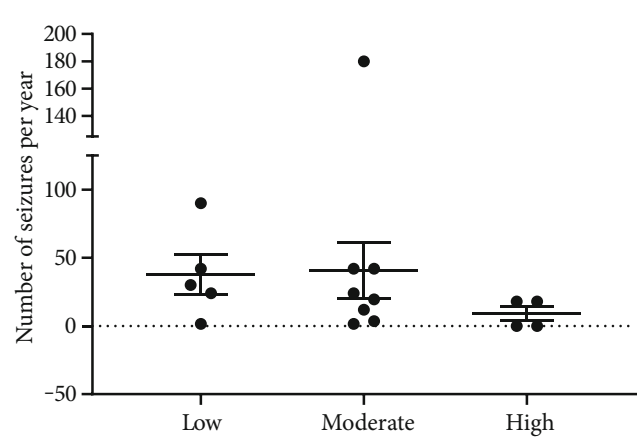

(b)

Figure 1: (a) Physical activity (MET) versus seizure frequency per year $\left(r=-0.5266,{ }^{*} p=0.0380\right.$, moderate negative correlation, Spearman's correlation test). The result indicates that physically active people tend to have fewer seizures. (b) Comparison of seizure frequency in PWE with three different exercise intensities (one-way ANOVA test, NS for all three groups with $p>0.999$ for low vs. moderate, $p=0.1406$ for low vs. high, $p=0.2420$ for moderate vs. high).

Perception of physical activity and seizure detection device: almost all PWE acknowledged the importance of exercise ( $>90 \%)$. Half of the patients responded to exercise regularly. Walking and yard work were the most preferred exercise. Also, the patients reported several potential barriers to exercise. Most patients (92\%) were unaware of seizure detection devices (embrace). Major barriers to purchasing seizure detection devices were the cost and uncertainty (Table 1(c)).

Types of seizures, current antiepileptic drugs (AEDs), and self-reported seizure frequency: the patients had various first onset of the seizure, with more than half of the patients experiencing seizure before age 18 . Some patients reported having $\geq 2$ types of seizures, which made the final percentage not equal to $100 \%$. Complex focal seizures and tonic-clonic seizures were the most common type of seizures. About one-third of patients did not know the type of seizure they had. Most patients had $<50$ seizures per year, with one patient having 180 seizures per year. Few patients could not report their seizure frequency. Carbamazepine, valproic acid, and levetiracetam were the top three most prescribed anticonvulsants. Most patients were on one to two anticonvulsants $(>70 \%)$. A few patients could not recall their current anticonvulsants (Table $1(\mathrm{~d})$ ).

\section{Discussion}

For our project, we designed our study to evaluate the effect of PA on seizure frequency, QOL, and medication adherence simultaneously for PWE at the EFWT. Additionally, we have obtained the demographic information, PWE's perception regarding physical activity, potential barriers to physical activity, and PWE's awareness of the seizure detection device. We have successfully achieved our primary and secondary outcome measurement through data collection of self-reported surveys and data analysis. Additionally, this project helped us assess the areas of care that potentially require improvement for PWE at the EFWT.

Overall, there was a statistically significant moderate negative correlation between physical activity (METminutes/week) and seizure frequency. This observation indi- cates that PWE who are physically active tend to have fewer seizures. Also, PWE in the high physical activity category had substantially lower seizure frequency than the other two groups with different physical intensities (low and moderate). Though there was no statistical significance, this could be due to a small sample size per group. Therefore, our overall results indicate an association between physical activity and seizure frequency in PWE.

The existing literature reported that physical activity was positively associated with QOL in PWE. For example, Hafele et al. reported a positive correlation between the amount of physical activity and QOL score in PWE [30]. Additionally, Volpato et al. reported physically active PWE having higher overall QOL than physically inactive PWE [22]. Our findings on physical activity and overall health matched this existing literature. As demonstrated in Figure 2(b), physical activity and overall health were the sole parameter of QOL with a statistically significant moderate positive correlation. As reported in the existing literature, our result indicates highly active PWE tend to have a better perception of their overall health than PWE with lower physical activity.

When Bonomi et al. conducted a study to validate the U.S. version of the WHOQOL, chronically ill patients with $\geq 1$ chronic condition for $\geq 1$ year and received medical care for the condition had lower QOL than healthy adults [48]. In this lieu, for our study, it is not surprising to discover PWE with $\geq 1$ chronic condition (e.g., epilepsy and other comorbidities) to have a similar QOL score as the chronically ill patients in the U.S. (Figure 3). Additionally, as reported in the existing literature, PWE in our study had significantly lower QOL scores than healthy individuals in the U.S. This observation is due to having comorbidity negatively affecting QOL. Yet, for QOL scores in PWE with different physical activity intensities (low, moderate, and high), highly active PWE had substantially higher QOL scores than the other groups. Also, this group had a statistically significant higher score in two domains (psychosocial health, environment) than the other two groups. Considering physical activity has a positive effect on psychological health (e.g., lowering anxiety and depression in PWE), this finding also matches up with the results from the existing 


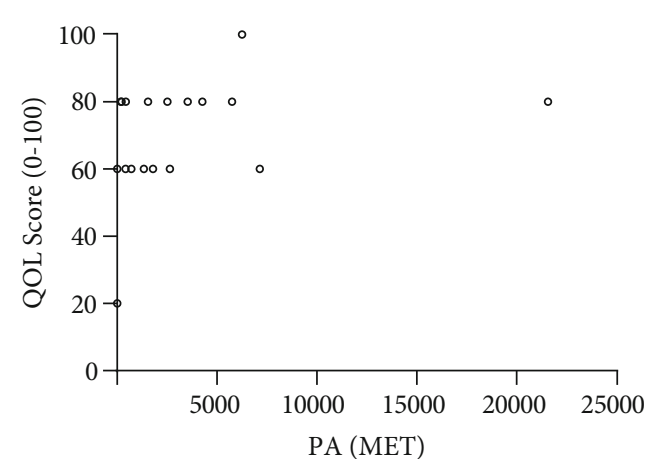

(a)

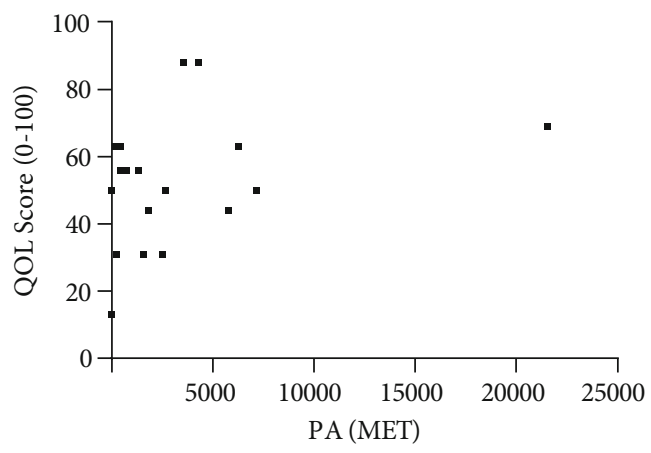

(c)

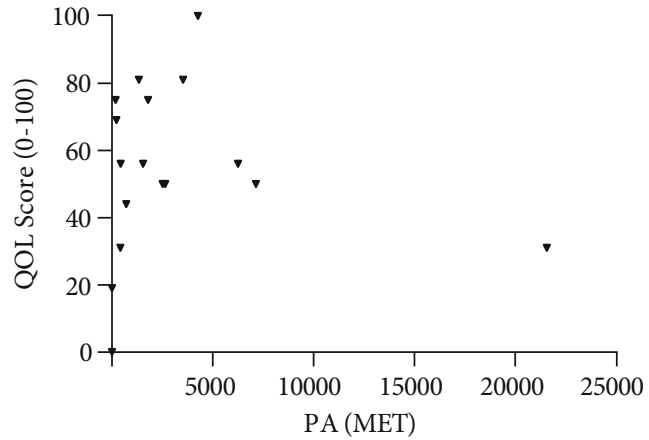

(e)

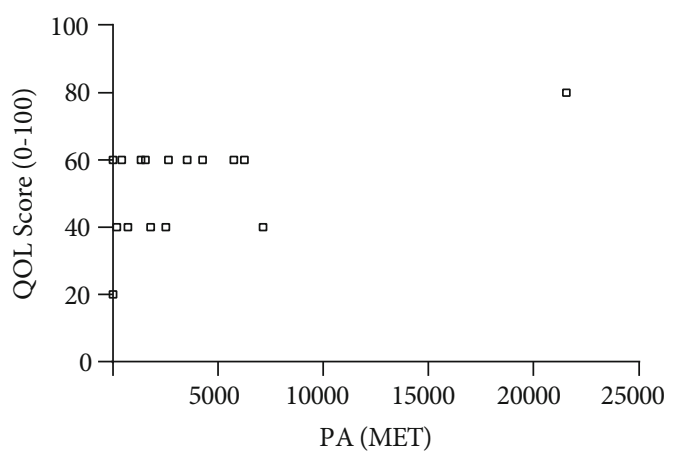

(b)

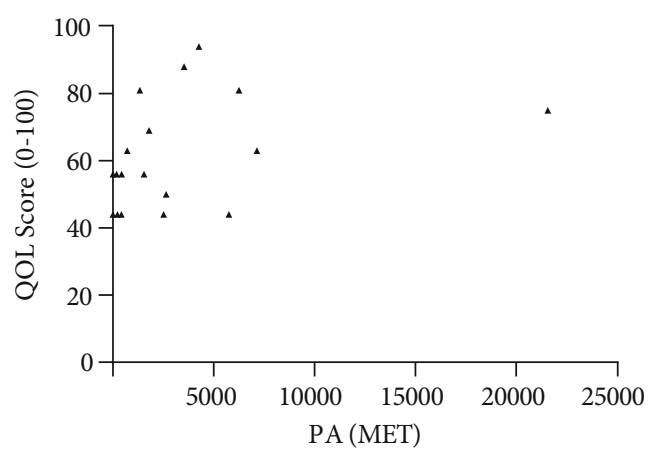

(d)

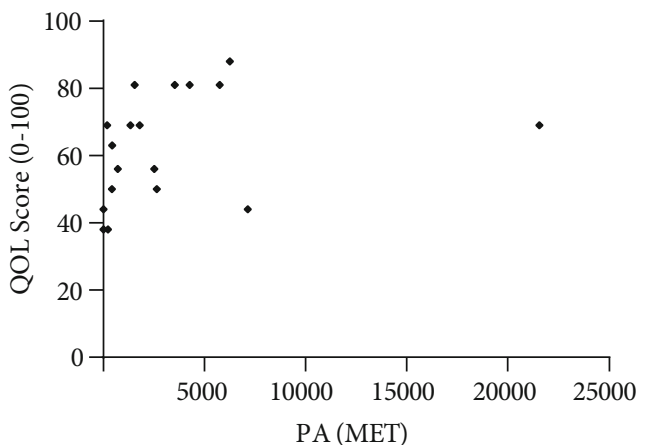

(f)

Figure 2: (a-f) Physical activity (MET) versus QOL score of six parameters. Pearson's correlation test $(r=0.3023, p=0.2228$ (a); $r=0.5388$, ${ }^{*} p=0.0210$ (b); $r=0.3194, p=0.1963$ (c), $r=0.3508, p=0.1535$ (d), $r=-0.0919, p=0.7257$ (e), $r=0.2839, p=0.2537$ (f).

literature and confirms the positive effect of PA on QOL in PWE $[22,30]$.

Overall, $52 \%$ of PWE were adherent to medication. This percentage falls within the usual medication adherence range for PWE [16-18]. Despite two patients with the most and the second most seizure frequencies in the nonadherent group, no difference in seizure frequency was observed between the medication adherent and medication nonadherent groups. This result contrasts the existing literature that has reported nonadherence to the anticonvulsants as one of the main precipitating factors for seizure triggers [49-51]. A low number of data collection for this survey is a potential explanation for this observation.

No difference in the QOL scores was observed between medication adherent and nonadherent groups. This result contrasts the several studies that have reported a positive association between medication adherence to anticonvul- sants and QOL $[52,53]$. Having one or more comorbidities for most PWE in our study could have an additional negative effect on the QOL for PWE at EFWT, which might not be attenuated by medication adherence alone. For example, a study that has reported a positive association between medication adherence and QOL only included PWE without any other comorbidities [53].

There was no difference in seizure frequency, physical activity, intensity, medication adherence, and QOLs between male and female subjects.

Demographic information, one of the secondary outcome measurements, helped us identify common comorbidities in PWE at EFWT. Obesity is reported by half of the survey respondents (47\%) and was one of the most common comorbidities, followed by arthritis and hypertension for PWE at EFWT. This finding matches the existing literature, which has reported higher comorbidities (obesity, arthritis, 


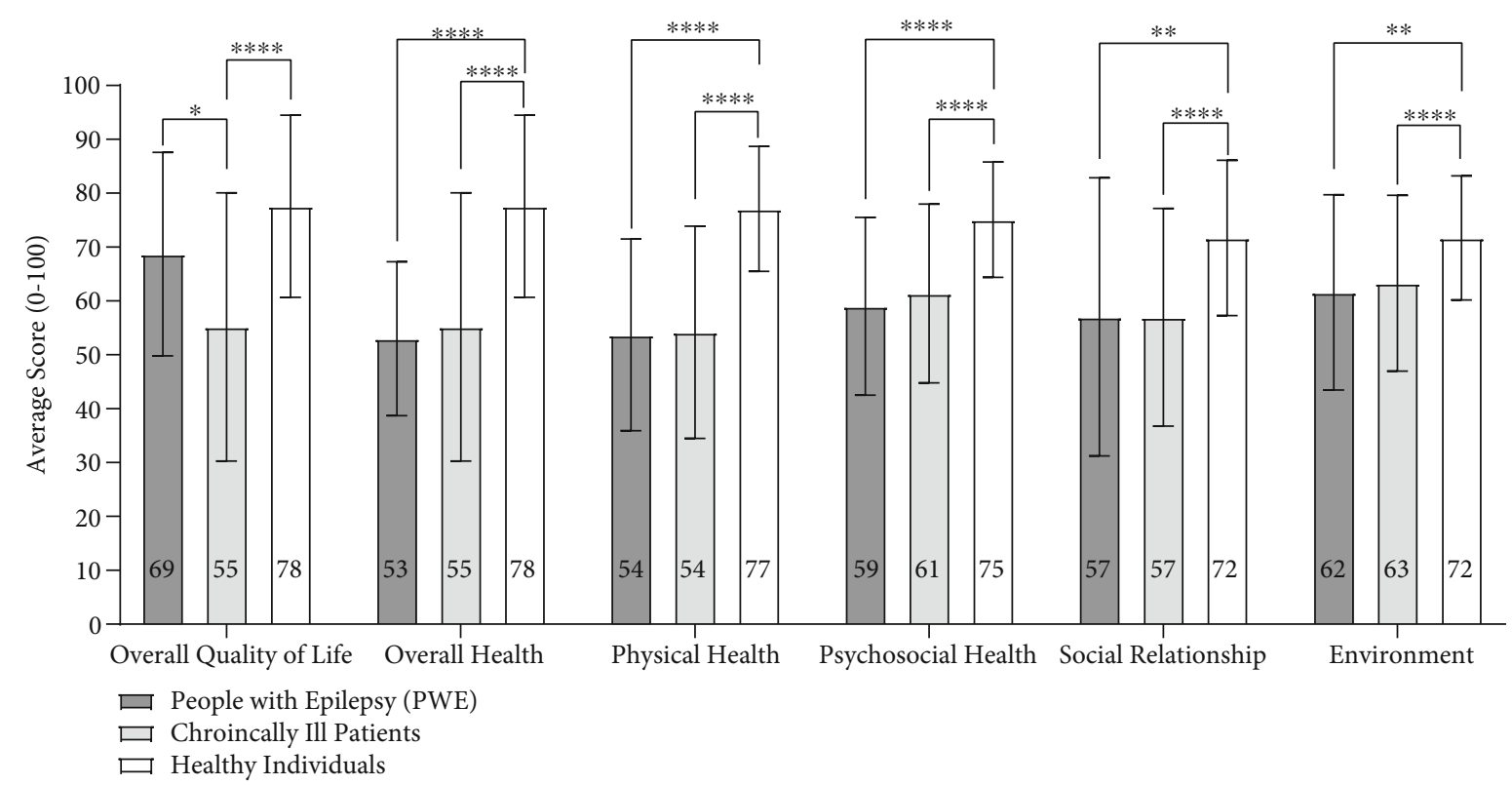

(a)

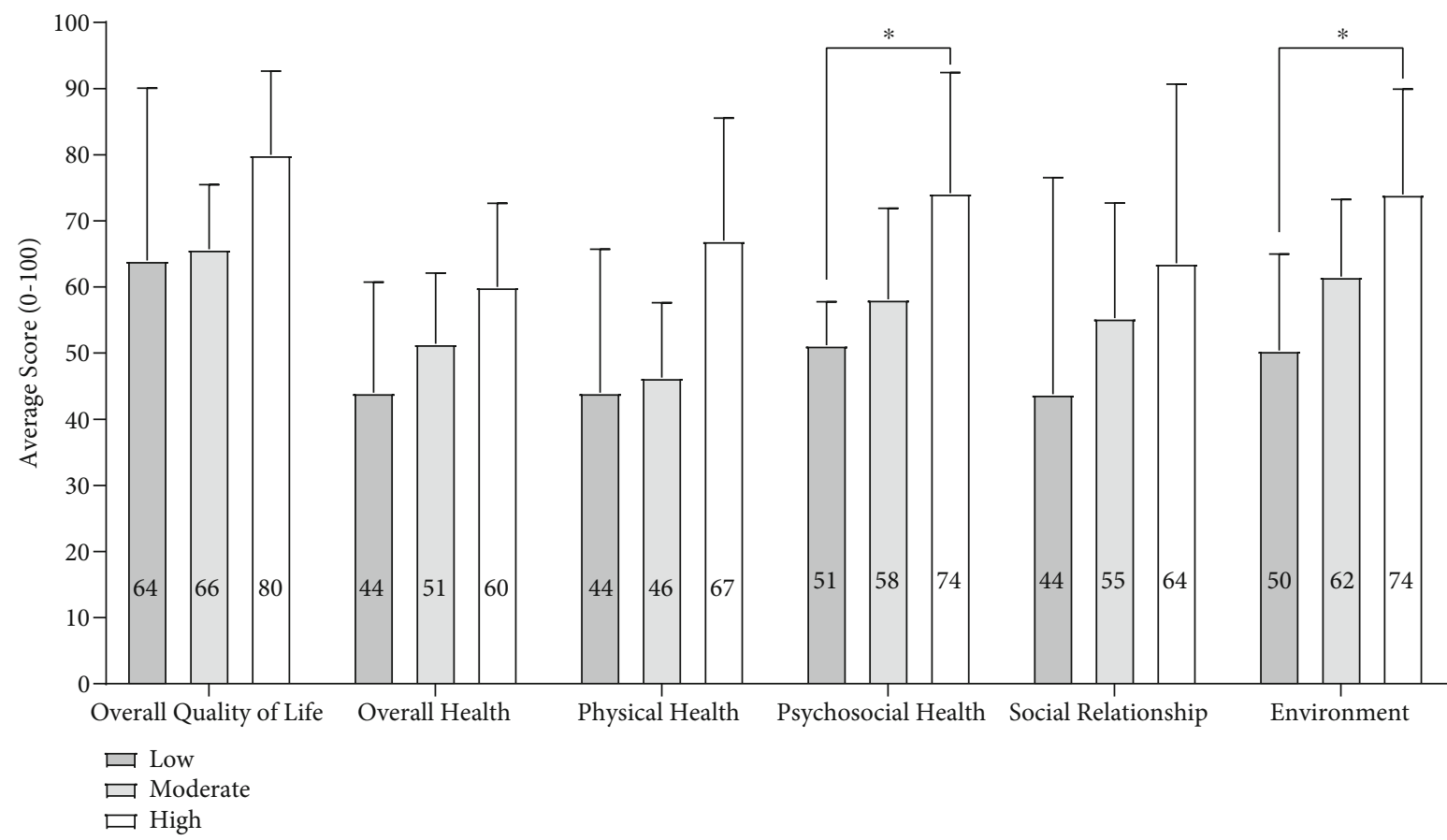

(b)

FIGURE 3: (a) Assessment and comparison of QOL in three groups (PWE, chronically ill, healthy individuals). Data for chronically ill patients and healthy individuals are obtained from literature to compare with PWE $\left({ }^{*} p<0.05,{ }^{* *} p<0.01,{ }^{* * *} p<0.001,{ }^{* * * *} p<0.0001\right.$, one-way ANOVA test). (b) Assessment and comparison of QOL in three groups with different exercise intensities $\left({ }^{*} p<0.05,{ }^{* *} p<0.01\right.$, ${ }^{* * *} p<0.001,{ }^{* * * *} p<0.0001$, one-way ANOVA test).

and hypertension) in PWE than the general population [54-58]. The potential causes of higher obesity in PWE than the general population include physical inactivity and adverse events from AED. Besides physical inactivity well known to contribute to obesity, certain anticonvulsants (e.g., gabapentin, pregabalin, valproic acid, and vigabatrin) stimulate appetite and induce sedation and lethargy, which lead to decreased physical activity and weight gain [59].
Additionally, since obesity is the known major risk factor for both hypertension and arthritis, including osteoarthritis and rheumatoid arthritis, this was an expected finding that $71 \%$ of the survey respondents with arthritis and $75 \%$ of the survey respondents with hypertension were either overweight or being obese [60-62]. Regarding physical activity, most PWE valued the importance of exercising (>90\%), with half of PWE at EFWT attempting to exercise regularly. 


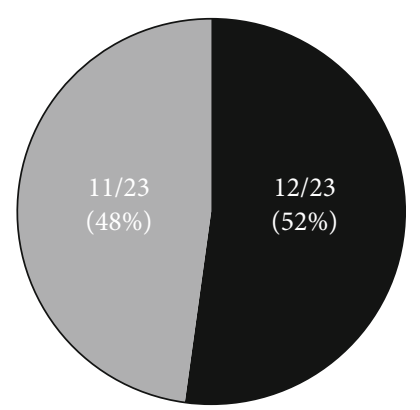

Adherent Non-adherent

(a)

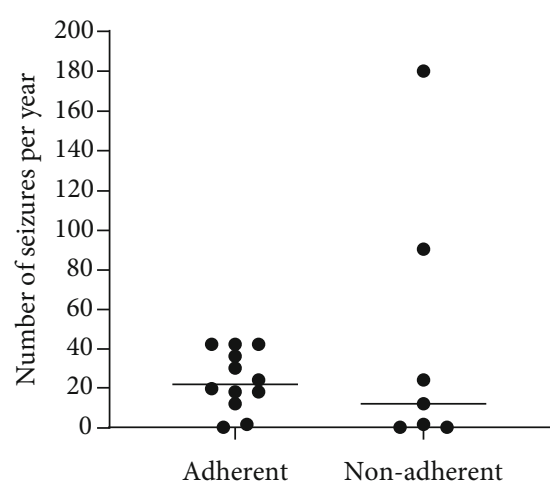

(b)

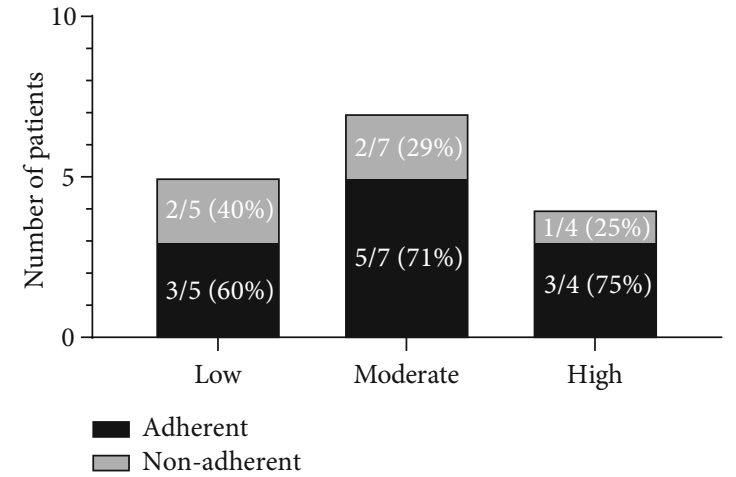

(c)

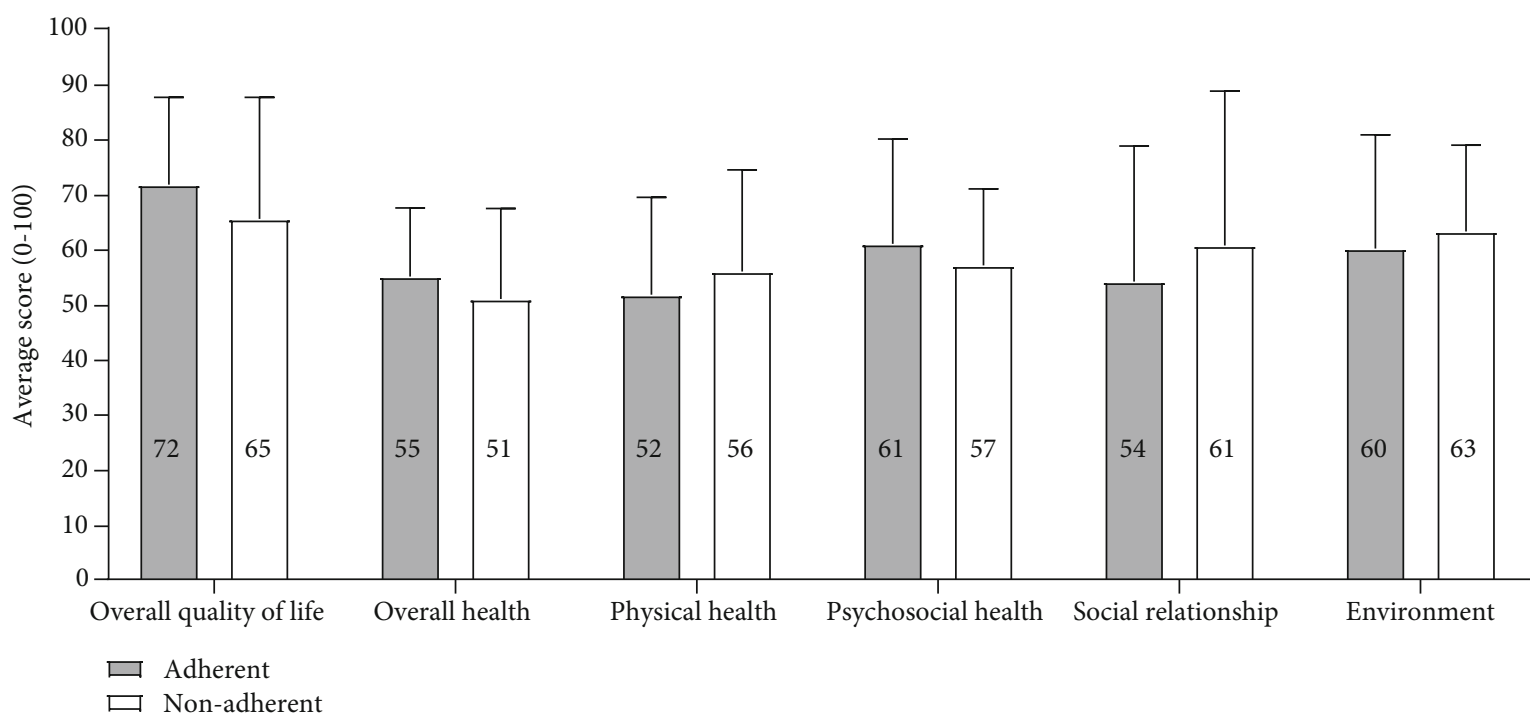

(d)

FIgURE 4: (a) Assessment for the percentage of adherent versus nonadherent to medication in PWE. (b) Assessment of medication adherence versus seizure frequency. Student's unpaired $t$-test $(p=0.6051)$. (c) Assessment of physical adherence versus medication adherence. Fisher's exact test ( $p>0.9999$ for all groups). (d) Assessment and comparison of QOL in two groups (adherent versus nonadherent). Student's unpaired $t$-test $(p=0.4439$ (overall QOL), $p=0.5053$ (overall health), $p=0.5796$ (physical health), $p=0.5821$ (psychosocial health), $p=0.5681$ (social relationship), $p=0.6913$ (environment)).

Exercise preference was primarily geared toward physical activities with a low risk of fall injuries such as walking and yard work. Physical disability or other disease conditions, fear of fall injury, the uncertainty of suitable exercise, and hard-to-find time for exercise were the most commonly reported potential barriers to exercise and were in line with reported in the literature $[38,40]$.

Only a few people were aware of the seizure detection device (Embrace). Furthermore, even people aware of the seizure detection device were uncertain how this device 


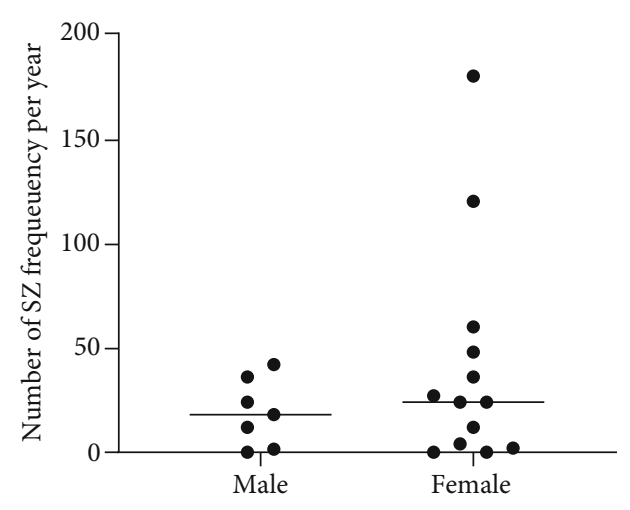

(a)

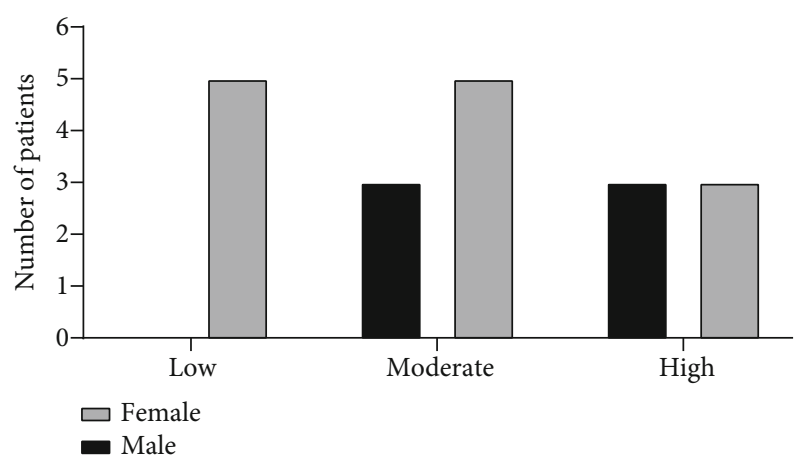

(c)

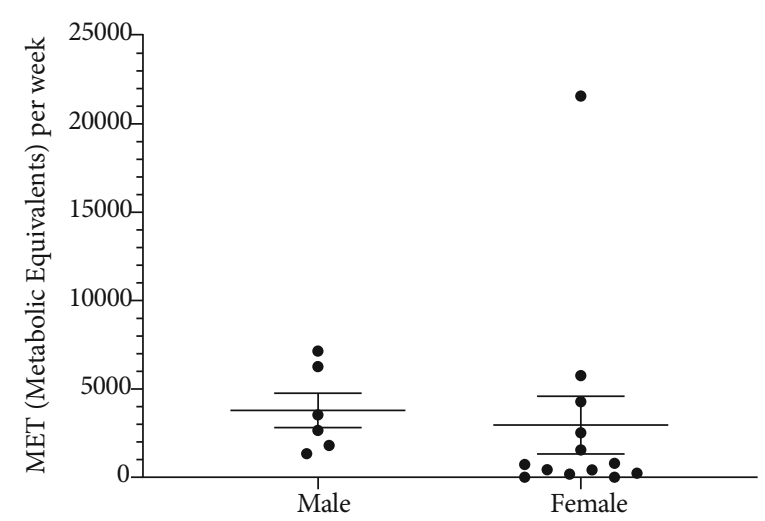

(b)

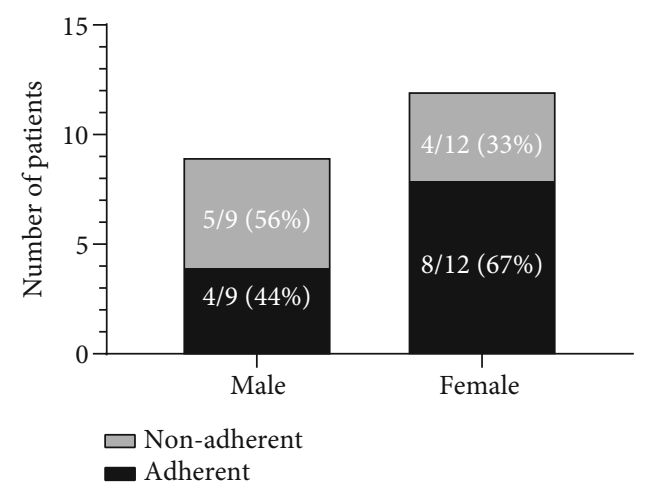

(d)

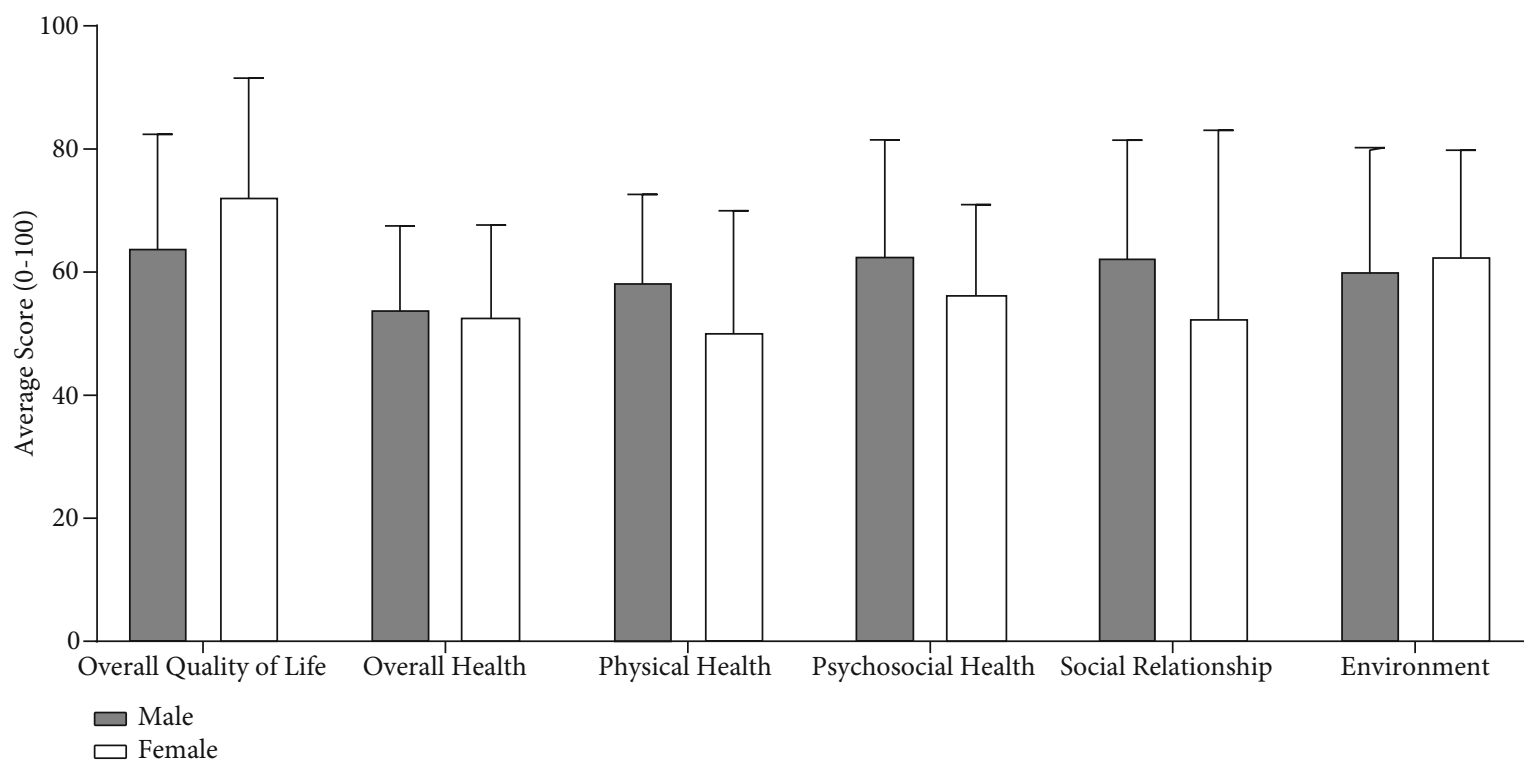

(e)

Figure 5: (a) Comparison of seizure frequency in two groups (male versus female). Mann-Whitney test $(p=0.4711$ ). (b) Comparison of MET-per week in two groups (male versus female). Student's unpaired $t$-test. $(p=0.7456)$. (c) Number of patients with different exercise intensities (low, moderate, and high) per group. Fisher's exact test $(p>0.9999$ for moderate vs. high, $p=0.1818$ for low vs. high, $p=$ 0.2308 for low vs. moderate). (d) Comparison of medication adherence between two groups (male versus female). Fisher's exact test $(p=0.3964)$. (e) Assessment and comparison of QOL in two groups (male versus female). Student's unpaired $t$-test ( $p=0.3069$ (overall QOL), $p=0.7854$ (overall health), $p=0.2756$ (physical health), $p=0.3776$ (psychosocial health), $p=0.3872$ (social relationship), $p=$ 0.7589 (environment)). 
TABLE 1

(a) General demographic information: basic information

\begin{tabular}{|c|c|}
\hline & $\begin{array}{c}\text { People with epilepsy (total } n=17 \\
\left.-24^{*}, \%\right)\end{array}$ \\
\hline Mean age \pm SD (range) & $39 \pm 14(19-70)$ \\
\hline \multicolumn{2}{|l|}{ Gender } \\
\hline Male & $10 / 24(42 \%)$ \\
\hline Female & $14 / 24(58 \%)$ \\
\hline \multicolumn{2}{|l|}{ Body mass index (BMI) } \\
\hline Underweight $(\leq 18.5)$ & $1 / 17(6 \%)$ \\
\hline Normal weight (18.5-24.9) & $6 / 17(35 \%)$ \\
\hline Overweight (25-29.9) & $2 / 17(12 \%)$ \\
\hline Obese $(\geq 30)$ & $8 / 17(47 \%)$ \\
\hline Obese class I (30.0-34.9) & $4 / 17(24 \%)$ \\
\hline Obese class $2(35-39.9)$ & $2 / 17(12 \%)$ \\
\hline Obese class $3(\geq 40)$ & $2 / 17(12 \%)$ \\
\hline \multicolumn{2}{|l|}{ Marital status } \\
\hline Single & $12 / 24(50 \%)$ \\
\hline Married & $5 / 24(20.8 \%)$ \\
\hline Divorced & $4 / 24(16.7 \%)$ \\
\hline $\begin{array}{l}\text { Engaged or in a } \\
\text { relationship }\end{array}$ & $3 / 24(12.5 \%)$ \\
\hline \multicolumn{2}{|l|}{ Ethnicity } \\
\hline White or Caucasian & $14 / 24(58.3 \%)$ \\
\hline Hispanic or Latino & $7 / 24(29.2 \%)$ \\
\hline Asian & $1 / 24(4.2 \%)$ \\
\hline Black or African American & $1 / 24(4.2 \%)$ \\
\hline $\begin{array}{l}\text { Other (mixed, White, and } \\
\text { Latino) }\end{array}$ & $1 / 24(4.2 \%)$ \\
\hline \multicolumn{2}{|l|}{ Health insurance } \\
\hline $\begin{array}{l}\text { Yes (e.g., Medicaid, } \\
\text { JOWYATT) }\end{array}$ & $14 / 24(58.3 \%)$ \\
\hline No & $10 / 24(41.7 \%)$ \\
\hline \multicolumn{2}{|l|}{ Education } \\
\hline $\begin{array}{l}\text { High school diploma or } \\
\text { GED }\end{array}$ & $17 / 24(70.8 \%)$ \\
\hline Some college credits & $3 / 24(12.5 \%)$ \\
\hline $\begin{array}{l}\text { Associate degree from } \\
\text { college }\end{array}$ & $1 / 24(4.2 \%)$ \\
\hline $\begin{array}{l}\text { Bachelor's degree from } \\
\text { college }\end{array}$ & $3 / 24(12.5 \%)$ \\
\hline \multicolumn{2}{|l|}{ Occupation } \\
\hline Employed & $6 / 24(25 \%)$ \\
\hline $\begin{array}{l}\text { Unemployed (e.g., } \\
\text { homebound) }\end{array}$ & $17 / 24(70.8 \%)$ \\
\hline Student & $1 / 24(4.2 \%)$ \\
\hline \multicolumn{2}{|l|}{ Income level } \\
\hline$\$ 0-\$ 5000$ & $15 / 24(62.5 \%)$ \\
\hline$\$ 5000-\$ 10,000$ & $1 / 24(4.2 \%)$ \\
\hline$\$ 10,000-\$ 20,000$ & $4 / 24(16.7 \%)$ \\
\hline$\$ 20,000-\$ 30,000$ & $2 / 24(8.3 \%)$ \\
\hline
\end{tabular}

TABLE 1: Continued.

People with epilepsy (total $n=17$ $\left.-24^{*}, \%\right)$

$\$ 30,000-\$ 40,000 \quad 2 / 24(8.3 \%)$

${ }^{*}$ For some questions, not all of them responded to the questions.

(b) General demographic information: health-related information

\begin{tabular}{lc}
\hline & $\begin{array}{c}\text { People with epilepsy (total } n= \\
\left.18-24^{*}, \%\right)\end{array}$ \\
\hline Other health conditions besides & \\
epilepsy** & \\
Arthritis & $7 / 18(38.9 \%)$ \\
Hypertension & $6 / 18(33.3 \%)$ \\
Asthma & $4 / 18(22.2 \%)$ \\
Migraine/headache & $4 / 18(22.2 \%)$ \\
None & $3 / 18(16.7 \%)$ \\
Liver problems (e.g., cirrhosis, & $2 / 18(11.1 \%)$ \\
fatty liver) & $2 / 18(11.1 \%)$ \\
Acid reflux/GERD & $2 / 18(11.1 \%)$ \\
Type 2 diabetes & $2 / 18(11.1 \%)$ \\
Heart failure & $2 / 18(11.1 \%)$ \\
Bipolar disorder & $1 / 18(5.6 \%)$ \\
Anxiety sensitivity & $1 / 18(5.6 \%)$ \\
Depression & $1 / 18(5.6 \%)$ \\
Sleep apnea & $1 / 18(5.6 \%)$ \\
IGA neuropathy & $1 / 18(5.6 \%)$ \\
Chronic bronchitis/COPD & $1 / 18(5.6 \%)$ \\
Hyperthyroidism & \\
Smoking & $9 / 24(37.5 \%)$ \\
$\quad$ Yes & $6 / 24(25 \%)$ \\
$\quad \leq 1 / 2$ pack per day & $2 / 24(8.3 \%)$ \\
$\quad$ No & $1 / 24(4.2 \%)$ \\
\hline
\end{tabular}

${ }^{*}$ For some questions, not all of them responded to questions. ${ }^{* *}$ Some patients had $\geq 2$ health conditions.

(c) General demographic information: perception of physical activity and seizure detection device

\begin{tabular}{lc}
\hline & $\begin{array}{c}\text { People with epilepsy } \\
\left.\text { (total } n=14-24^{*}, \%\right)\end{array}$ \\
\hline $\begin{array}{l}\text { Importance of exercise/physical } \\
\text { activity }\end{array}$ \\
Extremely important & $1 / 24(4.2 \%)$ \\
Very important & $6 / 24(25 \%)$ \\
Somewhat important & $15 / 24(62.5 \%)$ \\
Not so important & $1 / 24(4.2 \%)$ \\
Not at all important & $1 / 24(4.2 \%)$ \\
Exercise regularly & \\
Yes & $12 / 24(50 \%)$ \\
No & $12 / 24(50 \%)$ \\
\hline
\end{tabular}


TABLE 1: Continued.

\begin{tabular}{|c|c|}
\hline & $\begin{array}{l}\text { People with epilepsy } \\
\text { (total } n=14-24^{*}, \% \text { ) }\end{array}$ \\
\hline \multicolumn{2}{|l|}{ Types of exercise } \\
\hline Walking & $8 / 14(57.1 \%)$ \\
\hline Running & $1 / 14(7.1 \%)$ \\
\hline Yardwork & $2 / 14(14.3 \%)$ \\
\hline Standard exercise & $1 / 14(7.1 \%)$ \\
\hline No exercise/NA & $2 / 14(14.3 \%)$ \\
\hline \multicolumn{2}{|l|}{$\begin{array}{l}\text { Potential barriers to prevent physical } \\
\text { activity** }\end{array}$} \\
\hline Fear of fall injury & $5 / 21(24 \%)$ \\
\hline Uncertainty for suitable exercise & $4 / 21(19 \%)$ \\
\hline Hard to find time for exercise & $3 / 21(14 \%)$ \\
\hline $\begin{array}{l}\text { Physical disability or other disease } \\
\text { conditions }\end{array}$ & $6 / 21(29 \%)$ \\
\hline $\begin{array}{l}\text { Others (e.g., bad hips, tired/do not } \\
\text { feel well, always must have someone } \\
\text { with me, joint pain) }\end{array}$ & $5 / 21(24 \%)$ \\
\hline \multicolumn{2}{|l|}{$\begin{array}{l}\text { Aware of the seizure detection device } \\
\text { on the market }\end{array}$} \\
\hline Yes, but do not know the name & $1 / 24(4.2 \%)$ \\
\hline Yes (e.g., SeizureLink) & $1 / 24(4.2 \%)$ \\
\hline No & $22 / 24(91.7 \%)$ \\
\hline \multicolumn{2}{|l|}{$\begin{array}{l}\text { Purchased seizure detection device/ } \\
\text { reasons for not purchasing a device }\end{array}$} \\
\hline Yes & $0 / 2(0 \%)$ \\
\hline $\begin{array}{l}\text { No (e.g., cost, uncertain how it really } \\
\text { works) }\end{array}$ & $2 / 2(100 \%)$ \\
\hline \multirow{2}{*}{\multicolumn{2}{|c|}{$\begin{array}{l}{ }^{*} \text { For some questions, not all of them responded to questions. }{ }^{* *} \text { Som } \\
\text { patients had } \geq 2 \text { responses. } \\
\text { (d) General demographic information: characteristics of seizures } \\
\text { types, and the total number of anticonvulsants used }\end{array}$}} \\
\hline & \\
\hline & $\begin{array}{l}\text { People with epilepsy } \\
\text { (total } n=21-24^{*}, \% \text { ) }\end{array}$ \\
\hline \multicolumn{2}{|l|}{ Onset of seizure for the first time } \\
\hline Pediatric and adolescent (age $0-18$ ) & $13 / 24(54.2 \%)$ \\
\hline Adult $(\geq 18)$ & $9 / 24(37.5 \%)$ \\
\hline Unknown/not sure & $2 / 24(8.3 \%)$ \\
\hline \multicolumn{2}{|l|}{ Types of seizures** } \\
\hline \multirow{2}{*}{$\begin{array}{l}\text { Complex focal seizures (loss of } \\
\text { consciousness) }\end{array}$} & $10 / 21(47.6 \%)$ \\
\hline & $5 / 21(23.8 \%)$ \\
\hline \multirow{2}{*}{$\begin{array}{l}\text { Simple focal seizures (seizure } \\
\text { without loss of consciousness) }\end{array}$} & $7 / 21(33.3 \%)$ \\
\hline & $10 / 21(47.6 \%)$ \\
\hline $\begin{array}{l}\text { Generalized seizures (absence } \\
\text { seizures) }\end{array}$ & $3 / 21(14.3 \%)$ \\
\hline $\begin{array}{l}\text { Generalized seizures (tonic-clonic } \\
\text { seizures) }\end{array}$ & $1 / 21(4.8 \%)$ \\
\hline $\begin{array}{l}\text { Generalized seizures: atonic seizures } \\
\text { (also known as drop attacks) }\end{array}$ & $6 / 21(28.6 \%)$ \\
\hline Unknown/idiopathic & \\
\hline
\end{tabular}

TABle 1: Continued.

\begin{tabular}{|c|c|}
\hline & $\begin{array}{l}\text { People with epilepsy } \\
\text { (total } n=21-24^{*}, \% \text { ) }\end{array}$ \\
\hline \multicolumn{2}{|l|}{$\begin{array}{l}\text { Other (e.g., nocturnal seizure, do } \\
\text { not know) }\end{array}$} \\
\hline \multicolumn{2}{|l|}{ Seizure frequencies } \\
\hline $0-10$ per year & $6 / 24(25 \%)$ \\
\hline 11-24 per year & $6 / 24(25 \%)$ \\
\hline 25-48 per year & $8 / 24(33.3 \%)$ \\
\hline $60-120$ per year & $1 / 24(4.2 \%)$ \\
\hline 180 per year & $1 / 24(4.2 \%)$ \\
\hline Uncertain/unknown & $2 / 24(8.3 \%)$ \\
\hline Types of anticonvulsants used ${ }^{* *}$ & $\begin{array}{l}\text { People with epilepsy } \\
\left.\quad \text { (total } n=21^{*}, \%\right)\end{array}$ \\
\hline Brivaracetam & $1 / 21(4.8 \%)$ \\
\hline Carbamazepine & $8 / 21(38.1 \%)$ \\
\hline Clonazepam & $2 / 21(9.5 \%)$ \\
\hline Eslicarbazepine & $2 / 21(9.5 \%)$ \\
\hline Lacosamide & $1 / 21(4.8 \%)$ \\
\hline Levetiracetam & $3 / 21(14.3 \%)$ \\
\hline Perampanel & $1 / 21(4.8 \%)$ \\
\hline Phenobarbital & $1 / 21(4.8 \%)$ \\
\hline Phenytoin & $3 / 21(14.3 \%)$ \\
\hline Pregabalin & $1 / 21(4.8 \%)$ \\
\hline Topiramate & $1 / 21(4.8 \%)$ \\
\hline Valproic acid & $4 / 21(19.0 \%)$ \\
\hline Zonisamide & $1 / 21(4.8 \%)$ \\
\hline \multicolumn{2}{|c|}{$\begin{array}{l}\text { Total number of anticonvulsants used } \\
\text { per patient** }\end{array}$} \\
\hline One anticonvulsant & $9 / 21(42.9 \%)$ \\
\hline Two anticonvulsants & $6 / 21(28.6 \%)$ \\
\hline Three anticonvulsants & $1 / 21(4.8 \%)$ \\
\hline Four anticonvulsants & $2 / 21(9.5 \%)$ \\
\hline Unknown & $3 / 21(14.3 \%)$ \\
\hline
\end{tabular}

${ }^{*}$ For some questions, not all of them responded to questions. ${ }^{* *}$ Some patients had $\geq 2$ responses.

works and reluctant to purchase the device due to its high cost that could be due to the PWE at EFWT having low socioeconomic status with zero to low income. As a result, the price of a device (\$249) and a monthly subscription fee that ranges between $\$ 9.90$ and $\$ 44.90$ may not be affordable for PWE unless there is a form of financial assistance such as Medicare.

This project helped us identify the areas of care that potentially require improved PWE at the EFWT. Though most people acknowledged the importance of physical activity, specific potential barriers such as fear of fall injury and uncertainty for suitable exercise exist in PWE and make them less physically active. An exercise promoting programs such as Get FIT Texas has the potential to overcome these barriers under supervision by trained healthcare professionals [63]. From 2012 to 2017, this program provided fitness and healthy lifestyle coaching to PWE from the 
Epilepsy Foundation. PWE enrolled in this program had very favorable outcomes, such as $80 \%$ of the participants with improvement in BMI score, and $90 \%$ of participants scored higher on their quality of life tests after completion of the program. Therefore, reinstating the exercise program for PWE can improve both physical health and overall QOL in PWE.

Medication adherence and medication education are other areas of care that require improvement for PWE at the EFWT. In our study, almost half of the study participants were nonadherent to the medications. Furthermore, people had virtually little to no knowledge of other prescription medications, over-the-counter (OTC) drugs, or herbal supplements. To improve medication adherence, some resources to encourage medication adherence, such as $\mathrm{My}$ Seizure Diary and Texting 4 Control, the app, and a text message system designed to enhance medication adherence, can be utilized. Medication education or reconciliation programs can better the therapeutic management and reduce the risk of drug interactions [49, 64, 65].

Overall, PWE at EFWT had lower QOL than people without epilepsy. This finding is not surprising, considering epilepsy is reported to impact PWE's QOL negatively [22, 23]. Yet, it is good to observe QOLs be positively associated with a level of physical activity for PWE. Though there was no significant difference in QOLs for medication adherent PWE versus medication nonadherent PWE in our study, poor compliance with an anticonvulsant is the leading cause of the precipitated seizures and has a negative influence on QOLs of PWE. Therefore, it is essential to evaluate the QOLs regularly for PWE at EFWT and monitor other factors such as medication adherence and physical activity, the two factors known to influence QOLs of PWE.

4.1. Limitations. For this study, the data was collected from the EFWT. Therefore, the demographic information may differ for PWE reside in other regions. A low response rate, which was $12 \%$ (24 responses out of 150 patients), is a limitation of this study. Only limited patients were willing to answer the survey. Providing a form of small compensation may increase the response rate for future studies. It would have been surplus if seizure frequency was obtained using more accurate methods (e.g., electroencephalogram (EEG) and video-based telemetry). Yet, considering our study being an assessment study, it may be less crucial to obtain seizure frequency using objective method. Thus, subjective method such as a self-reported seizure frequency is still acceptable for our study. Still, our study is significant in a way that has evaluated the effect of PA and medication adherence on the QOL and seizure frequency of the PWE.

\section{Conclusion}

In conclusion, physical activity is positively associated with the quality of life and negatively associated with the seizure frequency for PWE at EFWT. However, unlike existing literature, there was no association between medication adherence and seizure frequency or QOL. The findings from this assessment study will be beneficial for EFWT to think of implementing certain programs (e.g., Get FIT Texas) to promote the well-being of the patients.

\section{Data Availability}

The datasets generated and/or analyzed during the current study are available from the corresponding author on reasonable request.

\section{Ethical Approval}

TTUHSC Quality Improvement Review Board (QIRB) determined this project as a program evaluation project that did not require further institutional review. A determination letter is available upon request.

\section{Consent}

Consent is not necessary.

\section{Conflicts of Interest}

The authors declare no competing interests.

\section{Authors' Contributions}

Y.L conceived the study and prepared the drafting of the manuscript. Y.A assisted with the manuscript proofreading and editing, statistical analysis, and generation of figures and tables. L.C helped with the drafting and editing of the manuscript and provided funding support. All authors reviewed the manuscript. All authors have read and agreed to the published version of the manuscript.

\section{Acknowledgments}

The authors would like to thank Dr. James Stoll, Ph.D., and Dr. Monica Mathys, Pharm.D., for their assistance in reviewing the manuscript and providing valuable feedback. Also, the authors would like to thank Shelley Spencer, LBSW, MSW, and Lucia Gandara, BSW, former and current social workers at Epilepsy Foundation, West Texas, for their assistance with data collection and a letter of support, Kaylee Youngblood, MLS, a librarian at TTUHSC, Amarillo, for preliminary literature search, and Justina Greene, for her assistance in translating the questionnaire into Spanish. The authors would also like to acknowledge the Epilepsy Foundation, West Texas, for their assistance and support of this project. Survey measures were informed in part by the Social and Behavioral Instruments (SABI) database developed by the University of North Carolina at Chapel Hill Center for AIDS Research, an NIH-funded program P30-AI50410. This work was supported by the National Institutes of Health/ National Institute on Drug Abuse 2R01DA029121-01A1, 1R01DA049737-01, and 1R01NS117906-01 to Dr. Luca Cucullo. 


\section{References}

[1] Centers for Disease Control and Prevention, Epilepsy Fast FactsJanuary 2020, https://www.cdc.gov/epilepsy/about/fastfacts.htm?CDC_AA_refVal=https\%3A\%2F\%2Fwww.cdc .gov\%2Fepilepsy\%2Fbasics\%2Ffast-facts.htm.

[2] Organization WHO, EpilepsyJanuary 2020, https://www.who .int/news-room/fact-sheets/detail/epilepsy.

[3] C. J. Murray, T. Vos, R. Lozano et al., "Disability-adjusted life years (DALYs) for 291 diseases and injuries in 21 regions, 1990-2010: a systematic analysis for the Global Burden of Disease Study 2010," Lancet, vol. 380, no. 9859, pp. 2197-2223, 2012.

[4] R. S. Fisher, C. Acevedo, A. Arzimanoglou et al., "ILAE official report: a practical clinical definition of epilepsy," Epilepsia, vol. 55, no. 4, pp. 475-482, 2014.

[5] R. S. Fisher, W. . E. Boas, W. Blume et al., "Epileptic seizures and epilepsy: definitions proposed by the International League Against Epilepsy (ILAE) and the International Bureau for Epilepsy (IBE)," Epilepsia, vol. 46, no. 4, pp. 470-472, 2005.

[6] G. Alarcón and A. Valentín, An Introduction to Epilepsy, E. B. Bromfield, J. E. Cavazos, and J. I. Sirven, Eds., Cambridge University Press, 2006.

[7] G. L. Holmes, "Cognitive impairment in epilepsy: the role of network abnormalities," Epileptic Disorders, vol. 17, no. 2, pp. 101-116, 2015.

[8] C. M. Marques, L. O. S. F. Caboclo, T. I. da Silva et al., "Cognitive decline in temporal lobe epilepsy due to unilateral hippocampal sclerosis," Epilepsy \& Behavior, vol. 10, no. 3, pp. 477485, 2007.

[9] R. Toledano and A. Gil-Nagel, "Adverse effects of antiepileptic drugs," Seminars in Neurology, vol. 28, no. 3, pp. 317-327, 2008.

[10] C. N. Gaspari and C. A. Guerreiro, "Modification in body weight associated with antiepileptic drugs," Arquivos de Neuro-Psiquiatria, vol. 68, no. 2, pp. 277-281, 2010.

[11] S. J. Petty, T. J. O'Brien, and J. D. Wark, “Anti-epileptic medication and bone health," Osteoporosis International, vol. 18, no. 2, pp. 129-142, 2007.

[12] K. Zeng, X. Wang, Z. Xi, and Y. Yan, “Adverse effects of carbamazepine, phenytoin, valproate and lamotrigine monotherapy in epileptic adult Chinese patients," Clinical Neurology and Neurosurgery, vol. 112, no. 4, pp. 291-295, 2010.

[13] G. A. Baker, "The psychosocial burden of epilepsy," Epilepsia, vol. 43, Supplement 6, pp. 26-30, 2002.

[14] C. DiIorio, P. Osborne Shafer, R. Letz et al., "The association of stigma with self-management and perceptions of health care among adults with epilepsy," Epilepsy \& Behavior, vol. 4, no. 3, pp. 259-267, 2003.

[15] M. Chesaniuk, H. Choi, P. Wicks, and G. Stadler, "Perceived stigma and adherence in epilepsy: evidence for a link and mediating processes," Epilepsy \& Behavior, vol. 41, pp. 227$231,2014$.

[16] I. E. Leppik, "How to get patients with epilepsy to take their medication. The problem of noncompliance," Postgraduate medicine, vol. 88, no. 1, pp. 253-256, 1990.

[17] R. M. Jones, J. A. Butler, V. A. Thomas, R. C. Peveler, and M. Prevett, "Adherence to treatment in patients with epilepsy: associations with seizure control and illness beliefs," Seizure, vol. 15, no. 7, pp. 504-508, 2006.
[18] E. Faught, "Adherence to antiepilepsy drug therapy," Epilepsy \& Behavior, vol. 25, no. 3, pp. 297-302, 2012.

[19] L. Stanaway, D. G. Lambie, and R. H. Johnson, "Non-compliance with anticonvulsant therapy as a cause of seizures," The New Zealand Medical Journal, vol. 98, no. 774, pp. 150-152, 1985.

[20] A. Boro and S. Haut, "Medical comorbidities in the treatment of epilepsy," Epilepsy \& Behavior, vol. 4, Supplement 2, pp. 212, 2003.

[21] M. Seidenberg, D. T. Pulsipher, and B. Hermann, "Association of epilepsy and comorbid conditions," Future Neurology, vol. 4, no. 5, pp. 663-668, 2009.

[22] N. Volpato, J. Kobashigawa, C. L. Yasuda, S. T. Kishimoto, P. T. Fernandes, and F. Cendes, "Level of physical activity and aerobic capacity associate with quality of life in patients with temporal lobe epilepsy," PLoS One, vol. 12, no. 7, article e0181505, 2017.

[23] H. H. Liou, R. C. Chen, C. C. Chen, M. J. Chiu, Y. Y. Chang, and J. D. Wang, "Health related quality of life in adult patients with epilepsy compared with a general reference population in Taiwan," Epilepsy Research, vol. 64, no. 3, pp. 151-159, 2005.

[24] S. Ramaratnam, G. A. Baker, and L. H. Goldstein, "Psychological treatments for epilepsy," Cochrane Database of Systematic Reviews, vol. 2, article CD002029, 2016.

[25] A. Gaitatzis, M. R. Trimble, and J. W. Sander, "The psychiatric comorbidity of epilepsy," Acta Neurologica Scandinavica, vol. 110, no. 4, pp. 207-220, 2004.

[26] C. J. Caspersen, K. E. Powell, and G. M. Christenson, "Physical activity, exercise, and physical fitness: definitions and distinctions for health-related research," Public Health Reports, vol. 100, no. 2, pp. 126-131, 1985.

[27] R. M. Arida, A. C. de Almeida, E. A. Cavalheiro, and F. A. Scorza, "Experimental and clinical findings from physical exercise as complementary therapy for epilepsy," Epilepsy \& Behavior, vol. 26, no. 3, pp. 273-278, 2013.

[28] J. Pimentel, R. Tojal, and J. Morgado, "Epilepsy and physical exercise," Seizure, vol. 25, pp. 87-94, 2015.

[29] J. W. McAuley, L. Long, J. Heise et al., "A prospective evaluation of the effects of a 12-week outpatient exercise program on clinical and behavioral outcomes in patients with epilepsy," Epilepsy \& Behavior, vol. 2, no. 6, pp. 592-600, 2001.

[30] C. A. Hafele, M. P. Freitas, M. C. da Silva, and A. J. Rombaldi, "Are physical activity levels associated with better health outcomes in people with epilepsy?," Epilepsy \& Behavior, vol. 72, pp. 28-34, 2017.

[31] K. Nakken, P. Bjørholt, S. Johannessen, T. LoSyning, and E. Lind, "Effect of physical training on aerobic capacity, seizure occurrence, and serum level of antiepileptic drugs in adults with epilepsy," Epilepsia, vol. 31, no. 1, pp. 88-94, 1990.

[32] H. R. Eriksen, B. Ellertsen, H. Gronningsaeter, K. O. Nakken, Y. Loyning, and H. Ursin, "Physical exercise in women with intractable epilepsy," Epilepsia, vol. 35, no. 6, pp. 1256-1264, 1994.

[33] M. Panebianco, K. Sridharan, and S. Ramaratnam, "Yoga for epilepsy," Cochrane Database of Systematic Reviews, vol. 10, article CD001524, 2017.

[34] C. Bernardi, A. C. Tramontina, P. Nardin et al., "Treadmill exercise induces hippocampal astroglial alterations in rats," Neural Plasticity, vol. 2013, Article ID 709732, 2013.

[35] A. M. Kelly, "Exercise-induced modulation of neuroinflammation in models of Alzheimer's disease," Brain Plast, vol. 4, no. 1, pp. 81-94, 2018. 
[36] J. L. Steiner, E. A. Murphy, J. L. McClellan, M. D. Carmichael, and J. M. Davis, "Exercise training increases mitochondrial biogenesis in the brain," Journal of Applied Physiology, vol. 111, no. 4, pp. 1066-1071, 2011.

[37] J. Nyberg, M. A. I. Aberg, K. Toren, M. Nilsson, E. Ben-Menachem, and H. G. Kuhn, "Cardiovascular fitness and later risk of epilepsy: a Swedish population-based cohort study," Neurology, vol. 81, no. 12, pp. 1051-1057, 2013.

[38] I. H. Dustin, B. Resnick, E. Galik et al., "The feasibility and impact of the EMOVE intervention on self-efficacy and outcome expectations for exercise in epilepsy," The Journal of Neuroscience Nursing, vol. 51, no. 2, pp. 95-100, 2019.

[39] G. M. Howard, M. Radloff, and T. L. Sevier, "Epilepsy and sports participation," Current Sports Medicine Reports, vol. 3, no. 1, pp. 15-19, 2004.

[40] S. S. Collard and C. Ellis-Hill, "How do you exercise with epilepsy? Insights into the barriers and adaptations to successfully exercise with epilepsy," Epilepsy \& Behavior, vol. 70, pp. 66-71, 2017.

[41] G. Capovilla, K. R. Kaufman, E. Perucca, S. L. Moshe, and R. M. Arida, "Epilepsy, seizures, physical exercise, and sports: a report from the ILAE Task Force on Sports and Epilepsy," Epilepsia, vol. 57, no. 1, pp. 6-12, 2016.

[42] F. Onorati, G. Regalia, C. Caborni et al., "Multicenter clinical assessment of improved wearable multimodal convulsive seizure detectors," Epilepsia, vol. 58, no. 11, pp. 1870-1879, 2017.

[43] L. M. Guilhoto, T. Loddenkemper, V. D. Gooty et al., "Experience with lacosamide in a series of children with drug-resistant focal epilepsy," Pediatric Neurology, vol. 44, no. 6, pp. 414-419, 2011.

[44] University of North Carolina at Chapel Hill Center for AIDS Research, Social and Behavioral Instruments (SABI) databasehttps://sabi.unc.edu.

[45] C. L. Craig, A. L. Marshall, M. Sjöström et al., "International physical activity questionnaire: 12-country reliability and validity," Medicine and Science in Sports and Exercise, vol. 35, no. 8, pp. 1381-1395, 2003.

[46] "Development of the World Health Organization WHOQOLBREF quality of life assessment. The WHOQOL Group," Psychological Medicine, vol. 28, no. 3, pp. 551-558, 1998.

[47] H. Knobel, J. Alonso, J. L. Casado et al., "Validation of a simplified medication adherence questionnaire in a large cohort of HIV-infected patients: the GEEMA study," AIDS, vol. 16, no. 4, pp. 605-613, 2002.

[48] A. E. Bonomi, D. L. Patrick, D. M. Bushnell, and M. Martin, "Validation of the United States' version of the World Health Organization Quality of Life (WHOQOL) instrument," Journal of Clinical Epidemiology, vol. 53, no. 1, pp. 1-12, 2000.

[49] I. Ernawati, W. R. Islamiyah, and Sumarno, "How to improve clinical outcome of epileptic seizure control based on medication adherence? A literature review," Journal of Medical Sciences, vol. 6, no. 6, pp. 1174-1179, 2018.

[50] N. Molugulu, K. S. Gubbiyappa, C. R. Vasudeva Murthy, L. Lumae, and A. T. Mruthyunjaya, "Evaluation of selfreported medication adherence and its associated factors among epilepsy patients in hospital Kuala Lumpur," Journal of Basic and Clinical Pharmacy, vol. 7, no. 4, pp. 105-109, 2016.

[51] S. Al-Aqeel, O. Gershuni, J. Al-Sabhan, and M. Hiligsmann, "Strategies for improving adherence to antiepileptic drug treatment in people with epilepsy," Cochrane Database of Systematic Reviews, vol. 2, article CD008312, 2017.

[52] C. Y. Lin, H. Chen, and A. H. Pakpour, "Correlation between adherence to antiepileptic drugs and quality of life in patients with epilepsy: a longitudinal study," Epilepsy \& Behavior, vol. 63, pp. 103-108, 2016.

[53] S. Hamedi-Shahraki, M. R. Eshraghian, M. S. Yekaninejad et al., "Health-related quality of life and medication adherence in elderly patients with epilepsy," Neurologia i Neurochirurgia Polska, vol. 53, no. 2, pp. 123-130, 2019.

[54] C. Hinnell, J. Williams, A. Metcalfe et al., "Health status and health-related behaviors in epilepsy compared to other chronic conditions-a national population-based study," Epilepsia, vol. 51, no. 5, pp. 853-861, 2010.

[55] R. Kobau, C. A. Dilorio, P. H. Price et al., "Prevalence of epilepsy and health status of adults with epilepsy in Georgia and Tennessee: behavioral risk factor surveillance system, 2002," Epilepsy \& Behavior, vol. 5, no. 3, pp. 358-366, 2004.

[56] R. Kobau, H. Zahran, D. J. Thurman et al., "Epilepsy surveillance among adults-19 states, behavioral risk factor surveillance system, 2005," MMWR Surveillance Summaries, vol. 57, pp. 1-20, 2008.

[57] L. D. Ladino, L. Hernandez-Ronquillo, and J. F. Tellez-Zenteno, "Obesity and its association with generalised epilepsy, idiopathic syndrome, and family history of epilepsy," Epileptic Disorders, vol. 16, no. 3, pp. 343-353, 2014.

[58] B. J. Steinhoff, K. Neususs, H. Thegeder, and C. D. Reimers, "Leisure time activity and physical fitness in patients with epilepsy," Epilepsia, vol. 37, no. 12, pp. 1221-1227, 1996.

[59] E. Ben-Menachem, "Weight issues for people with epilepsy-a review,” Epilepsia, vol. 48, Supplement 9, pp. 42-45, 2007.

[60] M. Blagojevic, C. Jinks, A. Jeffery, and K. P. Jordan, "Risk factors for onset of osteoarthritis of the knee in older adults: a systematic review and meta-analysis," Osteoarthritis and Cartilage, vol. 18, no. 1, pp. 24-33, 2010.

[61] S. Z. Jiang, W. Lu, X. F. Zong, H. Y. Ruan, and Y. Liu, “Obesity and hypertension," Experimental and therapeutic medicine, vol. 12, no. 4, pp. 2395-2399, 2016.

[62] K. M. Berry, T. Neogi, J. F. Baker et al., "Obesity progression between young adulthood and midlife and incident arthritis: a retrospective cohort study of US adults," Arthritis care \& research., vol. 73, no. 3, pp. 318-327, 2021.

[63] E. F. T. G. F. Texas, Epilepsy Foundation Texas - Get FIT Texashttps://tcdd.texas.gov/grants/grants-completed-projects/ epilepsy-foundation-texas/.

[64] R. AlAjmi, S. Al-Aqeel, and S. Baz, "The impact of a pharmacist-led educational interview on medication adherence of Saudi patients with epilepsy," Patient Preference and Adherence, vol. Volume 11, pp. 959-964, 2017.

[65] R. Marawar, M. Faraj, K. Lucas, C. V. Burns, and C. L. Garwood, "Implementation of an older adult epilepsy clinic utilizing pharmacist services," Journal of the American Pharmaceutical Association, vol. 61, no. 6, pp. e93-e98, 2021. 